\title{
Treatment outcomes of new smear positive pulmonary tuberculosis patients under directly observed treatment in Anambra State, Nigeria
}

\author{
Nwachukwu Obiora Ndubuisi ${ }^{1 *}$, Onyeagba Reginald Azu ${ }^{1}$, Nwaugo Victor Oluoha ${ }^{1}$ and Okafor Anthony ${ }^{2}$ \\ ${ }^{1}$ Department of Microbiology, Abia State University, P.M.B 2000, Uturu \\ ${ }^{2}$ Department of Animal and Environmental Biology, Abia State University, Uturu, P.M.B 2000, Uturu
}

\begin{abstract}
Objectives: Successful treatment of pulmonary tuberculosis patients is the key to tuberculosis control. This study aimed to assess treatment outcomes of newly diagnosed sputum smear-positive pulmonary tuberculosis patients under directly observed treatment, short course (DOTS) in Anambra State, Nigeria and determine factors associated with unsuccessful treatment outcome.

Methods: The prospective observational study was carried out at 3 TB/DOTS centres. A total of 213 newly diagnosed sputum smear-positive pulmonary tuberculosis patients were enrolled into the study. Diagnosis of pulmonary tuberculosis was based on Xpert MTB/RIF test and microscopy. Each patient was treated daily using a 6-month regimen recommended by WHO. For intensive phase, RHZE (150/75/400/275 mg) tablets were given for 2 months. RHZE contains the drugs rifampicin $(\mathrm{R})$, isoniazid $(\mathrm{H})$, pyrazinamide $(\mathrm{Z})$ and ethambutol(E). For contamination phase, RH (150/75mg) tablets were given for 4 months. The patients were followed up till completion of treatment and treatment outcomes recorded as per WHO guidelines.

Results: Out of 213 patients, $181(85 \%)$ were cured, treatment completed in 3(1.4\%) patients. Overall, treatment success rate was $86.4 \%$. Exactly 24 (11.3\%) patients were lost to follow up, treatment failed in $4(1.9 \%)$ and $1(0.5 \%)$ patient died. Treatment success rate decreased with aging as younger patients (15-24 years old) showed better treatment outcomes $(90 \%)$ than older patients $(\geq 65$ years) at $71.4 \%$. Unsuccessful treatment outcomes were more prevalent among unemployed patients (18.8\%), with no formal education (17.6\%) and married ones (12.6\%).

Conclusion: Treatment success rate in Anambra State was 86.4\%. Lost to follow up (default rate) was high (11.3\%). Aging, occupation and level of education were associated with unsuccessful treatment outcomes. It is therefore important to reduce default in treatment through proper counseling of pulmonary tuberculosis patients at TB/DOTS centres.
\end{abstract}

\section{Introduction}

The global burden of tuberculosis remains enormous as more than two billion people are currently infected by this disease, of which one in ten people with tuberculosis develop active tuberculosis [1]. The incidence rate of tuberculosis in Nigeria was 388 per 100,000 people in 2012 and more than half of them were smear-positive pulmonary tuberculosis [2]. Effective treatment is therefore essential to meet the goals of tuberculosis control and elimination [3].

It is important to achieve acceptable levels of treatment success among tuberculosis patients. Treatment success, therefore, has been measured by the number of patients being "cured" and those having "treatment completed [4]. The treatment success rate among all new tuberculosis cases was $86 \%$ globally [5]. However, a new International target of $90 \%$ treatment success has been set for the period 2015-2035 [6].

Tuberculosis control in Nigeria is based on directly observed treatment, short course strategy (DOTS). DOTS is the most widely accepted global health intervention for tuberculosis [9]. Treatment success rate in Nigeria has gradually increased over the last ten years to $86 \%$ in 2012, reaching the National target for 2015 [8]. Loss to follow up (default rate) decreased from $13 \%$ to $7 \%$ and death rate remained relatively low but constant around 5\% [8].
Assessing treatment of newly diagnosed smear-positive pulmonary tuberculosis patients is a useful indicator to evaluate effectiveness of interventions [9]. Unfortunately performance of four states in Nigeria is inadequate. These are Kwara, Lagos, Ogun and Anambra States [8]. In Kwara State, treatment success declined to $62 \%$ in 2012 while loss to follow up increased to 29\%. Lagos, Ogun and Anambra have unacceptably high rate of loss to follow up at $16 \%, 15 \%$ and $21 \%$ respectively.

Successful treatment of pulmonary tuberculosis has obvious benefits both to the individual patient and community but poor treatment outcomes has serious consequences of continuing infectivity on the community, development of multi-drug resistant tuberculosis and increased mortality $[10,11]$.

Some factors such as aging, drug abuse, alcohol abuse, HIV/AIDS,

Correspondence to: Dr. Nwachukwu Obiora Ndubuisi, Department of Microbiology, Abia State University, Uturu, P.M.B. 2000 Uturu. Tel: +2348033561693, Email: nwachukwundubuisi82@yahoo.com

Key words: treatment outcomes, TB/DOTS, pulmonary tuberculosis, Sputum smear-positive, Anambra State, Nigeria

Received: February 13; Accepted: March 14, 2017; Published: March 17, 2017 
ignorance of what tuberculosis is and poor qualities of medical services affect treatment of outcomes [3,12].

The objectives of this study therefore were to assess treatment outcomes of new sputum smear-positive pulmonary tuberculosis patients at different TB/DOTS centres in Anambra State, Nigeria and determine factors associated with unsuccessful treatment outcomes.

\section{Materials and methods}

\section{Study areas}

This prospective observational study was conducted at three locations namely Nnamdi Azikiwe University Teaching Hospital (NAUTH), Nnewi, Saint Charles Borromeo Hospital (SCBH), Onitsha and Endies Medical Laboratory (EML), Onitsha. NAUTH is a tertiary hospital with specialist care and a referral centre for other peripheral hospital; SCBH is a mission hospital with modern state-of-the art equipment whereas EML is a privately-owned laboratory located at a semi-urban area of Onitsha. All three facilities are integrated with National Tuberculosis and Leprosy Control Programme (NTBLCP) and provide free anti-tuberculosis medicines and services to the public.

\section{Study participants}

The study comprises 213 newly diagnosed sputum smear-positive pulmonary tuberculosis patients registered for directly observed treatment at the three TB/DOTS centres viz: NAUTH 113, SCBH 70 and EML 30 patients. Age of the patients ranged from 15 years to 76 years.

We included all newly diagnosed sputum smear-positive pulmonary tuberculosis patients who consented to participate in the study and were aged 15 years and older at the time of data collection. However, patients not willing to participate as well as terminally-ill ones were excluded.

\section{Methods}

Diagnosis of new smear-positive pulmonary tuberculosis was based on the National Tuberculosis Guidelines. At NAUTH and SCBH, presumptive TB cases submitted only one sputum sample which was processed directly from Xpert MTB/RIF test according to manufacturer's protocol. Interpretation of data from Xpert MTB/RIF test was software based [13]. At EML, presumptive TB cases submitted 2 sputum samples on the spot, within an hour interval. Smears were stained using Ziehl-Neelsen technique and Acid Fast Bacilli graded according to the recent WHO policy change [14].

All the new smear positive pulmonary tuberculosis patients were followed up at $2^{\text {nd }}, 5^{\text {th }}$ and $6^{\text {th }}$ months following chemotherapy. For follow up studies, each patient submitted only one sample.

\section{Pulmonary tuberculosis treatment and outcomes}

Each patient was treated daily using a 6-month regimen in line with WHO guidelines [15]. It consists of an intensive phase treatment for 2 months and a continuation phase for 4 months. For the Intensive Phase, RHZE (150/75/400/275 mg) tablets were given for 2 months. RHZE contains the drugs rifampicin $(\mathrm{R})$, isoniazid $(\mathrm{H})$, pyrazinamide (Z) and ethambutol (E). For Continuation Phase, RH(150/75 mg) tablets were given for 4 months. RH contains the drugs rifampicin (R) and isoniazid $(\mathrm{H})$. The number of tablets per dose was given according to a patient's weight (<39 kg: 2 tablets, $40-54 \mathrm{~kg}: 3$ tablets; $55-70 \mathrm{~kg}: 4$ tablets; $>70 \mathrm{~kg}: 5$ tablets [16]. A nurse at the TB/DOTS clinics observed patient intake of the medications.
Treatment outcomes were defined in accordance with standard WHO and National Tuberculosis definitions as follows: cured (a pulmonary tuberculosis patient with bacteriological confirmed TB at the beginning of treatment who was smear-or culture-negative in the last month of treatment and on at least on previous occasion), treatment completed (a TB patient who completed treatment without evidence of failure BUT with no record to show that sputum smear or culture results in the last month of treatment and on at least one previous occasion were negative, either because tests were not done or because results were unavailable), treatment failed (a TB patient whose sputum smear or culture is positive at month 5 or later during treatment), died (a TB patient who dies for any reason before starting or during the course of treatment, lost to follow up (a TB patient who did not start treatment or whose treatment was interrupted for 2 consecutive months or more), not evaluated (a TB patient for whom no treatment outcome is assigned $[16,17]$. This includes cases "transferred out" to another treatment unit as well as cases for whom the treatment outcome is unknown to the reporting unit), treatment success (the sum of cured and treatment completed). Treatment failed, died, lost to follow up, and not evaluated were categorized as unsuccessful treatment.

Data generated were analyzed using descriptive statistics including frequency tables and percentages. Chi-square test was used to compare study groups and $\mathrm{P}<0.05$ was considered significant.

Ethical clearance was obtained from ethical committees of both hospitals. A support letter was obtained from Abia State University to Endie's Medical Laboratories. All patients consented to participate in the study.

\section{Results}

A total of 213 new sputum smear-positive pulmonary tuberculosis patients, whose age ranged from 15 years to 76 years enrolled in the study. Majority of the patients (60\%) were males, traders $(70 \%)$ and married $(55.9 \%)$. More than half $(53 \%)$ of the patients were enrolled at NAUTH, Nnewi. The age group 25-34 years had more (37.6\%) pulmonary tuberculosis patients whereas the least infected (3.3\%) were in the age group of $\geq 65$ years (Table 1 ).

The treatment outcomes of the new smear-positive pulmonary tuberculosis patients in this study is presented in table 2 . The overall treatment success rate was $86.4 \%$. The summary of the treatment outcomes were as follows: cured (85\%), treatment completed $(1.4 \%)$, lost to follow up (11.3\%), treatment failed (1.9\%), died (0.5\%) and not evaluated $(0 \%)$.

There was no difference in treatment success rates (86.7 vs. $85.9 \%)$ between males and female patients $(\mathrm{p}>0.05)$. However, the proportion of treatment success differed at TB/DOTS centres: $87.6 \%$ at NAUTH, Nnewi and $80.0 \%$ at EML, Onitsha. This difference was not significant $(\mathrm{p}>0.05)$.

Treatment success rate decreased with age as younger patients (1524 years old) showed better outcomes $(90 \%)$ than older patients ( $>65$ years old) at $71.4 \%$. Unsuccessful outcomes were more prevalent in unemployed patients (81.8\%), with no formal education (17.6\%) and married (12.6\%) as shown in table 3.

\section{Discussion}

Successful treatment of new sputum smear-positive pulmonary tuberculosis patients is the hallmark of any intervention. In this study, treatment success rate was $86.4 \%$, which was closer to $87 \%$ target among all new sputum smear-positive pulmonary tuberculosis patients 
globally in 2013 [5]. But slightly lower than the new International target of $90 \%$ set for the period $2015-2035$ by the WHO [6]. The treatment success rate in our study was however higher than the rate obtained in other parts of Nigeria: $78.5 \%$ in Abuja $77.1 \%$ in Ebonyi state $[18,19]$. Our finding was similar to $84.4 \%$ at Debre Berham Hospital Ethiopia [20]. This implies that the quality of DOTS services in Anambra state has improved through time.

The cure rate was $85 \%$, meeting the WHO cure rate of $85 \%$ set in 2005 [5]. Our result was higher than $76.6 \%$ obtained in similar studies in Ibadan and $61.4 \%$ in Abuja Nigeria $[11,18]$. The care received at this $\mathrm{TB} / \mathrm{DOTS}$ centres is thought to be superior, given that two of the TB/ DOTS centres are tertiary health institutions. The result was also higher than cure rate of $18 \%$ in Addis Ababa, Ethiopia and $15.9 \%$ at Debre Berham Hospital, Northern Ethiopia [20,22]. The difference was that the participants in the Ethiopian study included both pulmonary and extrapulmonary cases which might have affected the cure rate.

Table 1. Sociodemographic characteristics of new smear- positive pulmonary tuberculosis patients from 3 TB/DOTS centres in Anambra State, Nigeria.

\begin{tabular}{|c|c|c|}
\hline \multicolumn{3}{|c|}{$\mathrm{n}=\mathbf{2 1 3}$} \\
\hline Characteristic & MTB/AFB+ & $\%$ \\
\hline \multicolumn{3}{|l|}{ Gender } \\
\hline Males & 128 & 60 \\
\hline Females & 85 & 40 \\
\hline \multicolumn{3}{|l|}{ TB/DOTS centre } \\
\hline NAUTH, Nnewi & 113 & 53.0 \\
\hline SCBH, Onitsha & 70 & 32.9 \\
\hline Endie's Lab, Onitsha & 30 & 14.1 \\
\hline \multicolumn{3}{|c|}{ Age group (years) } \\
\hline $15-24$ & 30 & 14.1 \\
\hline $25-34$ & 80 & 37.6 \\
\hline $35-44$ & 55 & 25.8 \\
\hline $45-54$ & 27 & 12.7 \\
\hline $55-64$ & 14 & 6.6 \\
\hline$>65$ & 7 & 3.3 \\
\hline \multicolumn{3}{|c|}{ Level of education } \\
\hline No formal & 102 & 47.9 \\
\hline Primary & 64 & 30.0 \\
\hline Secondary & 26 & 12.2 \\
\hline Tertiary & 21 & 9.9 \\
\hline \multicolumn{3}{|l|}{ Marital status } \\
\hline Single & 73 & 34.3 \\
\hline Married & 119 & 55.9 \\
\hline Divorced/widowed & 21 & 9.9 \\
\hline \multicolumn{3}{|c|}{ Occupation } \\
\hline Trading/Business people & 149 & 70.0 \\
\hline Civil servants & 17 & 8.0 \\
\hline Students & 36 & 16,9 \\
\hline Unemployed & 11 & 5.2 \\
\hline
\end{tabular}

Table 2. Treatment outcomes of new smear-positive pulmonary tuberculosis patients on DOTS treatment in Anambra State, Nigeria.

\begin{tabular}{|c|c|c|}
\hline \multicolumn{2}{|c|}{$\mathbf{n = 2 1 3}$} \\
\hline Treatment outcome & No of patients & $\mathbf{\%}$ \\
\hline Treatment success & 184 & 86.4 \\
\hline Lost to follow up (default) & 24 & 11.3 \\
\hline Treatment failed & 4 & 1.9 \\
\hline Died & 1 & 0.5 \\
\hline Transferred out & 0 & 0 \\
\hline Cured & 181 & 85 \\
\hline Treatment completed & 3 & 1.4 \\
\hline
\end{tabular}

Table 3. Distribution of treatment outcome by sociodemographic characteristics.

\begin{tabular}{|c|c|c|c|}
\hline \multicolumn{4}{|c|}{$\mathrm{n}=\mathbf{2 1 3}$} \\
\hline Variable & $\begin{array}{c}\text { Successful outcome } \\
(\%)\end{array}$ & $\begin{array}{l}\text { Unsuccessful } \\
\text { outcome (\%) }\end{array}$ & Total \\
\hline \multicolumn{4}{|c|}{ Gender } \\
\hline Males & 111(86.7) & $17(13.3)$ & 128 \\
\hline Females & $73(85.9)$ & $12(14.1)$ & 85 \\
\hline \multicolumn{4}{|c|}{ TB/DOTS centre } \\
\hline NAUTH, Nnewi & $99(87.6)$ & $14(12.4)$ & 113 \\
\hline SCBH, Onitsha & $61(87.1)$ & $9(12.9)$ & 70 \\
\hline EML, Onitsha & $24(80.0)$ & $6(20.0)$ & 30 \\
\hline \multicolumn{4}{|c|}{ Age group (years) } \\
\hline $15-24$ & $27(90)$ & $3(10.0)$ & 30 \\
\hline $25-34$ & $73(91.3)$ & $7(8.75)$ & 80 \\
\hline $35-44$ & $46(83.6)$ & $9(16.4)$ & 55 \\
\hline $45-54$ & $22(81.5)$ & $5(18.5)$ & 27 \\
\hline $55-64$ & $11(78.6)$ & $3(21.4)$ & 14 \\
\hline$>65$ & $5(71.4)$ & $2(28.6)$ & 7 \\
\hline \multicolumn{4}{|c|}{ Level of Education } \\
\hline No formal & $84(82.4)$ & $18(17.6)$ & 102 \\
\hline Primary & $56(87.5)$ & $8(12.5)$ & 64 \\
\hline Secondary & $56(92.3)$ & $2(7.7)$ & 26 \\
\hline Tertiary & $20(95.2)$ & $1(4.8)$ & 21 \\
\hline \multicolumn{4}{|c|}{ Marital status } \\
\hline Single & $67(91.8)$ & $6(8.2)$ & 73 \\
\hline Married & $104(87.4)$ & $15(12.6)$ & 119 \\
\hline Divorced/widowed & $19(90.5)$ & $2(9.5)$ & 21 \\
\hline \multicolumn{4}{|c|}{ Occupation } \\
\hline $\begin{array}{l}\text { Trading/Business } \\
\text { people }\end{array}$ & $128(85.9)$ & $21(14.1)$ & 149 \\
\hline Civil servants & $15(88.2)$ & $2(11.8)$ & 17 \\
\hline Students & $32(88.9)$ & $4(11.1)$ & 36 \\
\hline Unemployed & $9(81.2)$ & $2(18.8)$ & 11 \\
\hline
\end{tabular}

Lost to follow up (default rate) was $11.3 \%$ in Anambra state. This was higher than $8 \%$ observed in Ethiopia [20]. The National default rate decreased from 13\% to 7\% in 2012 but lost to follow up in Anambra state remained unacceptably high at $21 \%$ [8]. This finding however, has shown some improvement over time in Anambra State. The high rate of default in the state may be due to poor counseling of patients at DOTS clinics, poor knowledge and attitude towards DOTS. An earlier study in Anambra State identified reason for default in diagnosis as belief in the efficacy of prayer house healing for pulmonary tuberculosis [3]. This reason could also be true for treatment thus contributing to default. To reduce lost to follow up in the state, the authorities should resort to community engagement and proper motivation of staff at DOTS centres.

In this study, treatment failed in only $4(1.9 \%)$ patients. This was an improvement in a study in Abuja, Nigeria where treatment failure was $4 \%$ but higher than $0.5 \%$ in North West Ethiopia [18,21]. There is a natural tendency for patients to quit treatment as soon as they felt better [23]. To reduce treatment failure in new smear-positive pulmonary tuberculosis patients, the use of treatment supporters at health facilities and at home would help ensure proper treatment adherence [24].

Only one patient $(0.5 \%)$ died in the course of this study. This could be attributed to exclusion of terminally-ill patients from the study and/ or low population size of study participants. The low death rate could also highlight DOTS as an effective intervention.

Unsuccessful treatment outcomes in this study was mainly associated with aging, occupation and educational status of the patients. In this regard, a higher proportion of unsuccessful treatment 
outcome was seen in patients older than 65 years. This is in agreement with those of other studies $[19,25,26]$. The higher rate of unsuccessful treatment outcome observed among elderly patients may be due to multi-morbidity of pulmonary tuberculosis with diabetes mellitus and cardiovascular diseases. This study, did not however, evaluate multimorbidity among these newly diagnosed smear-positive patients.

Patients who were unemployed showed higher unsuccessful treatment outcome (18.8\%) than other occupational classes. The reason for this finding could be a result of higher risk of TB infection in this class, coupled with low self-esteem and health seeking behavior [27].

Patients with no formal education had a higher rate (17.6\%) of unsuccessful treatment outcome. This is consistent with the report of Akintola et al. that non-compliance are associated with poor education of patients on TB therapy [11]. It is also similar to the finding of Ukwaja et al. that low knowledge of TB and therapy is a predictive factor of adverse treatment outcome among tuberculosis patients [27]. Enhanced patient counseling and education on tuberculosis will help reduce unsuccessful treatment outcomes.

In conclusion, the treatment success rate in Anambra State was $86.4 \%$. Lost to follow up was high at $11.3 \%$. Aging, occupation and level of education of the patients were associated with unsuccessful treatment outcomes. It is therefore important to reduce default in treatment through proper counseling of new smear-positive pulmonary tuberculosis patients at TB/DOTS centres.

\section{References}

1. Shafee M, Abbas F, Ashraf M, Alam Mengal M, Kakar N, et al. (2014) Hematological profile and risk factors associated with pulmonary tuberculosis patients in Quetta, Pakistan. Pak J Med Sci 30: 36-40. [Crossref]

2. Federal Ministry of Health (FMOH) (2010) Department of Public Health: National Tuberculosis and Leprosy Control Programme. Workers Manual revised.

3. Ndubuisi NO, Chibuike OA, Esther UA, Christopher OU (2016) Delay in diagnosis of pulmonary tuberculosis among presumptive tuberculosis cases in pats of Anambra State, Nigeria. J Emerg Infect Dis 1:120.

4. World Health Organization (2013a) Factsheet No 104 updated Oct 6th 2013. Geneva, Switzerland.

5. World Health Organization (2014) Global Tuberculosis Report, 2014. Geneva 2014.

6. World Health Organization (2015) Global Strategy and targets for tuberculosis prevention, care and control after 2015. WHO, Geneva.

7. World Health Organization (2006) Global Plan to Stop TB 2011-2015. Daves, Switzerland: WHO 2006.

8. NTBLCP Report (2016) The National Strategic Plan for Tuberculosis Control. Towards Universal Access to Prevention, Diagnosis and Treatment (2015-2020). Nigeria. 55-70.

9. Sharma A, Dinesh K, Kiran K, Parveen KS, Rekha B et al. (2016) Treatment outcome of new smear-positive patients of pulmonary tuberculosis treated under DOTS in a rural tertiary care hospital of a hilly area. Int J Community Med Pub Health 3: 2129-2132.
10. Salman K, Jafar H, Shahab R, Ebrahim G, Somayeh K et al (2016) Treatment outcome of new smear positive pulmonary patients in Hamadan, Iran: A registry-based crosssectional study. Egyptian J Ches Dis Tuberc 65: 825-830.

11. Akinola AF, Abimbola SO, Afolabi EB (2009) Treatment outcomes among pulmonary tuberculosis patients at treatment centres in Ibadan, Nigeria. Ann Afr Med 8: 100-104 [Crossref]

12. Jiang RH, Xu HB, Fu J (2015) Outcome of Chinese herb medicine for the treatment of multi-drug-resistant tuberculosis: a systemic review and meta-analysis. Complement Ther Med 23: 544-554. [Crossref]

13. Boehme CC, Nabeta P, Hillemann D, Nicol MP, Shenai S, et al. (2010) Rapid molecular detection of tuberculosis and rifampin resistance. N Engl J Med 363: 1005 1015. [Crossref]

14. World Health Organization (2010a) Framework for implementing new tuberculosis diagnosis. Geneva, Switzerland.

15. World Health Organization (2010b) Treatment of tuberculosis guidelines. 4th Edition. Geneva: WHO 1-92.

16. Federal Ministry of Health, Nigeria (2010) National Tuberculosis and Leprosy Control Programme: Workers Manual. Revised 5th edition. Abuja: Federal Ministry of Health. 1-119.

17. World Health Organization (2013b) Definitions and reporting framework for tuberculosis -2013 revision 2013. WHO Geneva.

18. Onyebuchi SO, Berhrand BO (2015) Treatment outcome of tuberculosis patients at National Hospital Abuja Nigeria: a five year retrospective study. South Afr Fam Prat 57:1

19. Oshi DC, Oshi SN, Alobu I, Ukwaja KN (2014) Profile and treatment outcomes of tuberculosis in the elderly in southeastern Nigeria, 2011-2012. PLoS One 9: e111910. [Crossref]

20. Firdie T, Tariku D, Tsegaye T (2016) Treatment outcomes of tuberculosis patients at Debre Berhan hospital, Amhara Region, Northern Ethiopia. Ethiop J Health Sci 26:6572. [Crossref]

21. Endris M, Moges F, Belyhum Y, Woldehana E, Esmael, A et al. (2014) Treatment outcome of tuberculosis patients at enfraz health centre, northwest Ethiopia: a five-year retrospective study. Tuberc Res Treat: 5. [Crossref]

22. Belete G, Gobena A, Girmay M, Sibliatu B (2013) Treatment outcome of tuberculosis patients under directly observed treatment in Addis Ababa, Ethiopia. Braz J Infect Dis 17: 521-528. [Crossref]

23. Tessemba B, Muche A, Bekele A (2009) Treatment outcome of tuberculosis patients at Gondar University Teaching Hospital, Northwest Ethiopia. A five-year retrospective study. BMC Pub Health 9: 371-378. [Crossref]

24. World Health Organization (2007) Tuberculosis Care with TB-HIV Co-management WHO Report No 310: 41 Geneva.

25. Khazaei S1, Roshanaei G1, Saatchi M1, Rezaeian S2, Zahiri A3, et al. (2014) The epidemiological aspects of tuberculosis in Hamadan Province during 2005-11. Int J Health Policy Manag 2: 75-80. [Crossref]

26. Shahrezaei M, Maracy MR, Farid F (2015) Factors Affecting Mortality and Treatmen Completion of Tuberculosis Patients in Isfahan Province from 2006 to 2011. Int J Prev Med 6: 91. [Crossref]

27. Ukwaja KN, Alobu I, Nweke CO, Onyenwe EC (2013) Health-Seeking behavior, treatment delays and its determinants among pulmonary tuberculosis patients in rural Nigeria: A cross-sectional study. BMC Health Serv Res 13: 25. [Crossref]

Copyright: (C2017 Ndubuisi NO. This is an open-access article distributed under the terms of the Creative Commons Attribution License, which permits unrestricted use, distribution, and reproduction in any medium, provided the original author and source are credited. 